\title{
SAINT-JOHN PERSE
}

(31 de mayo de 1887-20 de septiembre de 1975)

ACASO la historia entera de la poesía no ha tenido un protagonista tan digno de homenaje - y aun de loa-como Saint-John Perse (seudónimo de Marie-René Alexis SaintLéger Léger). En un islote que era entonces propiedad de su familia ("Saint-Léger-les-Feuilles"), situado a la altura de Pointe-a-Pitre, en el mar de las Antillas, ve la luz un niño de excepción, un dios-infante que muchos años después y con noble desdén, habría de rechazar el título que quiso otorgarle un destacado grupo de literatos franceses: "Príncipe de las letras de Francia".

La prodigiosa exuberancia de su tierra natal despierta en el niño un vasto afán de conocimiento: botánica, humanidades, zoología, geología, antropología, historia... Al mismo tiempo, el joven Léger practica el alpinismo, la equitación, la esgrima; hace innumerables viajes en barco... Casi no hay un renglón del conocimiento humano que no sea recorrido por el dedo puntual y sensible de un ser que se arroba ante todo lo animado y todo aquello que injustamente- consideramos insensible.

Se trata de un conquistador nato. Su entrada en las letras con Elogios equivale a sentar una piedra miliar sobre la que habrá de construirse todo un imperio poético. Su paso por el mundo de la diplomacia no es menos asombroso. Durante algún tiempo, Perse suspende la publicación de sus obras; luego, al salir de la diplomacia (rumbo a su exilio estadounidense) la reanuda. Cada uno de sus libros (Anábasis, Lluvias, Nieves, Pájaros, Vientos, Mares...) es singular porque está habitado más que ningún otro por el 
aliento vital de nuestro planeta. Quien toma por primera vez un libro suyo siente en sus manos la densidad viviente del orbe, su palpitación sensible irrigada de mares, el ígneo clima que declara la vida más plena e intensa.

En celebración de su primer renacimiento hemos querido presentar aquí una muestra de su obra poética y epistolar, así como el testimonio que a su obra rinde un poeta de la elevada jerarquía de René Char. Ni qué decir tiene: honrarlo como conviene al filo del espiritu es algo imposible.

José Luis Rivas 